\title{
Adhesive Bonding of Resin Cements to Cast Titanium with Adhesive Primers
}

\author{
Marina DI FRANCESCANTONIO ${ }^{1}$ \\ Marcelo Tavares de OLIVEIRA ${ }^{2}$ \\ Luiz Gustavo Dias DAROZ3 \\ Guilherme Elias Pessanha HENRIQUES ${ }^{4}$ \\ Marcelo GIANNINI ${ }^{1}$ \\ ${ }^{1}$ Department of Restorative Dentistry, Piracicaba Dental School, \\ UNICAMP - University of Campinas, Piracicaba, SP, Brazil \\ ${ }^{2}$ Nove de Julho University, São Paulo, SP, Brazil \\ ${ }^{3}$ Department of Prosthodontics, UFES - Federal University of Espirito Santo, Vitória, ES, Brazil \\ ${ }^{4}$ Department of Prosthodontics and Periodontics, Piracicaba Dental School, \\ UNICAMP - University of Campinas, Piracicaba, SP, Brazil
}

\begin{abstract}
The purpose of this study was to evaluate the effects of adhesive primer applications on the bond strength of resin cements to cast titanium. Four adhesive primers - Metaltite, Metal Primer II, Alloy Primer and Ceramic Primer - and their respective resin cements Bistite II DC, Link Max, Panavia F 2.0, RelyX Unicem and RelyX ARC - were tested. Cast plates were prepared from titanium ingots $(\mathrm{n}=6$ specimens/cement) and had their surfaces airborne-particle abraded with Al2O3 $(50 \mu \mathrm{m})$. Three resin cement cylinders were built on each bonded titanium surface, using a cylindrical translucent tubing mold and were subjected to micro-shear testing. Data were analyzed statistically by two-way ANOVA and Tukey's post-hoc test $(\alpha=0.05)$. The application of Metal Primer II and Ceramic Primer resulted in significant higher bond strength for Link Max and RelyX Unicem resin cements, respectively, than nonuse of adhesive primers. Panavia F 2.0 and RelyX ARC yielded high bond strength means with or without adhesive primers. The use of adhesive primers might increase the bond strength to cast titanium depending on the resin cement used.
\end{abstract}

Key Words: Dental alloys, titanium, resin cements, tensile strength.

\section{INTRODUCTION}

Pure titanium or titanium alloys have been used in dentistry for complete crowns, and metal frameworks for fixed partial, implant-supported and removable dentures. The increasing use of this metal in clinical Prosthodontics is due to the development of new casting machines and techniques (1-3).

Although titanium has many advantages, such as, biocompatibility, high corrosion resistance and good mechanical properties (4-6), there are concerns regarding the weak bonding between luting materials and cast titanium when adhesive luting is indicated (7). In an attempt to enhance the bonding to titanium, some materials and techniques have been suggested $(2,3,8$ 19). However, the problems of achieving a durable and predictable bond between titanium and luting material still remain.

Chemical and mechanical bonding techniques have been proposed to treat titanium surface before cementation. Chemical bonding systems using functional monomers or silane-couplers have been suggested for bonding to titanium $(9,11,18,20,21)$ while surface modification by Silicoater or Rocatec techniques and micro-mechanical retention produced by air abrasion or electrolytic etching are other treatments suggested for adhesive bonding $(11,22)$.

The purpose of this study was to evaluate the effects of adhesive primers on the shear bond strength of dual-cured resin cementing systems to cast titanium. The null hypothesis tested was that bond strength is not influenced by the adhesive primer application regardless

Correspondence: Prof. Dr. Marcelo Giannini, Departamento de Odontologia Restauradora, Faculdade de Odontologia de Piracicaba, UNICAMP, Avenida Limeira, 901, 13414-903 Piracicaba, SP, Brasil. Tel: +55-19-2106-5340. Fax: +55-19-2106-5218. e-mail: giannini@fop.unicamp.br 
the type of dual-cured resin cement used.

\section{MATERIAL AND METHODS}

Sixty commercially pure titanium (Tritan; Dentaurum J.P. Winkelstroeter KG, Pforzheim, Germany) plates (10 mm long x $5 \mathrm{~mm}$ wide x $1 \mathrm{~mm}$ thick) were cast and randomly divided into 10 groups $(n=6)$. Acrylic resin patterns (Pattern Resin LS; GC Corp., Tokyo, Japan) with the plate dimensions were invested using titanium investment material (Rematitan; Dentaurum, Baden-Württemberg, Germany) with a ratio of $250 \mathrm{~g}$ of powder to $40 \mathrm{~mL}$ of liquid. The mixing was carried out under vacuum at a speed of $425 \mathrm{rpm}$ for 30 s using a mechanical mixer (Multivac 4; DeguDent, $\mathrm{GmbH}$, Hanau, Germany). The investment blocks (Rematitan; Dentaurum) were heated according to the manufacturer's instructions in an electric furnace (Vulcan 3.550; DeguDent) with a heating rate of $5^{\circ} \mathrm{C} /$ min, following the cycle: $250^{\circ} \mathrm{C} / 90 \mathrm{~min}, 900^{\circ} \mathrm{C} / 40 \mathrm{~min}$, and afterwards, cooling within the furnace (Vulcan
3.550; DeguDent) at a rate of $5^{\circ} \mathrm{C} / \mathrm{min}$ for the target temperature of $430^{\circ} \mathrm{C}$, which was maintained for 90 min. Castings were performed in an arc-melting titanium vacuum casting machine (Dentaurum) using $31 \mathrm{~g}$ ingots and 0.95 bar argon pressure.

After casting, the investment blocks were immediately quenched in cold water and castings were recovered with the aid of an airborne-particle abrasion unit (Microetcher IITM; Danville Engineering Inc., San Ramon, CA, USA) using $50 \mu \mathrm{m}$-aluminum oxide particles (Pasom Inc., São Paulo, SP, Brazil) for $5 \mathrm{~s}$ at 5.5 bar. Sprues were removed with a separating disk (Dentaurum) and the external surfaces of the frameworks were finished with tungsten carbide burs (Dentaurum) at low speed. The titanium plates were airborne-particle abraded with $50 \mu \mathrm{m}$ aluminum oxide for $5 \mathrm{~s}$ at 80 -psi pressure with the nozzle $5 \mathrm{~mm}$ from the surface (11), one day before the bonding procedures.

Materials used in the bonding procedures are described in Table 1. Four adhesive primers - Metaltite (Tokuyama Dental Corp., Tokyo, Japan), Metal Primer

Table 1. Compositions of resin cements and adhesive primers.

\begin{tabular}{|c|c|}
\hline Material & Composition \\
\hline $\begin{array}{l}\text { Bistite II DC } \\
\text { (Resin cement) }\end{array}$ & $\begin{array}{l}\text { Base: neopentyldimethacrylate, silica-zirconia, activators. } \\
\text { Catalyst: MAC-10, neopentyldimethacrylate, silica-zirconia, initiators. }\end{array}$ \\
\hline LinkMax & Fluoroaluminosilicate glass, urethane dimethacrylate, HEMA, silica. \\
\hline $\begin{array}{l}\text { Panavia F } 2.0 \\
\text { (Resin cement) }\end{array}$ & $\begin{array}{l}\text { Paste A: MDP, hydrophobic aromatic dimethacrylates, hydrophobic aliphatic dimethacrylates, } \\
\text { hydrophilic aliphatic dimethacrylates, silanated silica filler, silanated colloidal silica, } \\
\text { dl-camphoroquinone, initiators. } \\
\text { Paste B: hydrophobic aromatic dimethacrylates, hydrophobic aliphatic dimethacrylates, hydrophilic } \\
\text { aliphatic dimethacrylates, silanated barium glass filler, initiators, accelerators, pigments. }\end{array}$ \\
\hline $\begin{array}{l}\text { RelyX Unicem } \\
\text { (Resin cement) }\end{array}$ & $\begin{array}{l}\text { Catalyst: glass powder, substituted dimethacrylate, silane-treated silica, } \\
\text { sodium p-toluenesulfinate, calcium hydroxide. } \\
\text { Base: glass powder, methacrylated phosphoric acid esters, triethylene glycol dimethacrylate, } \\
\text { silane-treated silica, sodium persulfate. }\end{array}$ \\
\hline $\begin{array}{l}\text { RelyX ARC } \\
\text { (Resin cement) }\end{array}$ & $\begin{array}{l}\text { Paste A: silane treated ceramic, triethylene glycol dimethacrylates, BisGMA, silane treated silica, } \\
\text { functionalized dimethacrylate polymer, photoinitiators, amine, pigments. } \\
\text { Paste B: silane treated ceramic, triethylene glycol dimethacrylates, BisGMA, silane treated silica, } \\
\text { functionalized dimethacrylate polymer, benzoic peroxide. }\end{array}$ \\
\hline Metaltite (primer) & 6-methacryloyloxyhexyl-2-thiouracil-5-carboxylate (MTU-6), ethanol, initiator. \\
\hline Metal Primer II (primer) & Thiophosphoric methacrylate (MEPS), methylmethacrylate (MMA). \\
\hline Alloy Primer (primer) & 6-(4-vinylbenzyl-N-propyl) amino-1,3,5-triazine-2,4-dithione (VBATDT), MDP, acetone. \\
\hline Ceramic Primer (primer) & Gama-methacryloxypropyl trimethoxysilane, ethanol, water. \\
\hline
\end{tabular}


II (GC Corp.), Alloy Primer (Kuraray Medical Inc., Kurashiki, Japan) and Ceramic Primer (3M ESPE, St. Paul, MN, USA) - and their respective resin cements Bistite II DC (Tokuyama Dental Corp.), LinkMax (GC Corp.), Panavia F 2.0 (Kuraray Medical Inc.), RelyX Unicem (3M ESPE) and RelyX ARC (3M ESPE) - were evaluated, using the adhesive primer and resin cement from the same company. Ceramic Primer (3M ESPE) was used with RelyX Unicem and RelyXARC. Adhesive primers and resin cements were applied and handled according to manufacturers' instructions. All lightactivation was performed with the XL 3000 light curing unit (3M ESPE), under standard irradiation mode and $650 \mathrm{~mW} / \mathrm{cm}^{2}$. Light output was monitored throughout the course of the experiment with a curing radiometer (Optilux; Kerr-Sybron, GmbH, Karlsruhe, Germany).

The methodology developed by Shimada et al. (21) was used to prepare specimens for the micro-shear test. Three cylindrical translucent molds (Tygon tubing TYG-030; Saint-Gobain Performance Plastic, Miame Lakes, FL, USA) were positioned over the titanium surface plate that was primed or not and freshly mixed dual-cure resin cements were inserted into the molds, using a modified composite spatula (Duflex \#3; SS White, Juiz de Fora, MG, Brazil). The resin cement cylinders were irradiated from the top for $40 \mathrm{~s}$.

Specimens were stored in distilled water at $37^{\circ} \mathrm{C}$ for $24 \mathrm{~h}$. The tube molds were removed to expose the resin cement cylinders $(0.75 \mathrm{~mm}$ diameter $x 0.5 \mathrm{~mm}$ high) bonded to the metal surface. Three bonded resin cement cylinders were obtained for each titanium plate. Prior to testing, all resin cylinders were evaluated under an optical microscope $(\times 30$ magnfication) (Nikon Measurescope, Tokyo, Japan) for bonding defects.

Each titanium plate was attached to the testing device with cyanoacrylate glue (Super Bonder; Loctite, Itapevi, SP, Brazil) and tested in a universal testing

Table 2. Mean bond strength values in MPa (SD) of resin cements to titanium.

\begin{tabular}{lcc}
\hline Resin Cements & With Primer & Without Primer \\
\hline Panavia F 2.0 & $45.4(11.4) \mathrm{ABa}$ & $44.1(6.9) \mathrm{Aa}$ \\
LinkMax & $53.5(7.8) \mathrm{Aa}$ & $30.8(5.2) \mathrm{Bb}$ \\
Bistite II DC & $33.2(6.3) \mathrm{BCa}$ & $29.3(2.06) \mathrm{Ba}$ \\
RelyX Unicem & $47.5(2.4) \mathrm{Aa}$ & $31.9(5.1) \mathrm{ABb}$ \\
RelyX ARC & $29.6(7.8) \mathrm{Ca}$ & $24.3(8.7) \mathrm{Ba}$ \\
\hline
\end{tabular}

machine (4411; Instron Corp., Canton, MA, USA). A shear load was applied to the base of the resin cement cylinder with a thin wire $(0.20 \mathrm{~mm}$ diameter $)$ at a crosshead speed of $0.5 \mathrm{~mm} / \mathrm{min}$ until failure. Shear bond strengths were calculated and expressed in $\mathrm{MPa}$. Three bond strength measurements were recorded for each titanium plate and the mean bond strength was determined for each experimental unit. Results were statistically analyzed by two-way (adhesive primer application and resin cement factors) analysis of variance (ANOVA) and Tukey's post hoc test $(\alpha=0.05$ ) using the SAS analytical software (SAS Institute, Cary, NC, USA).

\section{RESULTS}

The mean shear bond strength values and standard deviations are presented in Table 2. Two-way ANOVA revealed that there were statistically significant differences for the factor "adhesive primer" $(\mathrm{p}=0.00007)$, for the factor "resin cement" $(\mathrm{p}=0.00002)$ and for the interaction between factors $(\mathrm{p}=0.00525)$.

According to Tukey's post-hoc test, the application of Metal Primer II and Ceramic Primer increased significantly $(p<0.05)$ the bond strength of LinkMax and RelyX Unicem resin cements to cast titanium, respectively, when compared with nonapplication of adhesive primers. For the other resin cements, adhesive primer application had no effect on bond strength to titanium ( $\mathrm{p}>0.05)$.

With primer applications, Panavia F 2.0, LinkMax and RelyX Unicem showed significantly higher $(\mathrm{p}<0.05)$ bond strength to cast titanium than RelyX ARC resin cement. Without primer, Panavia F 2.0 resin cement yielded significantly higher $(\mathrm{p}<0.05)$ bond strength than Bistite II DC, LinkMax and RelyX ARC, but it was not significantly different from RelyX Unicem ( $p>0.05)$.

\section{DISCUSSION}

The results of this study indicate that two primed surfaces yielded higher bond strength of resin cements to titanium than non-use of adhesive primers. Although the bond strength of two resin cements tested was significantly influenced by the use of the adhesive primers before resin cement application, the null hypothesis was rejected, since the adhesive primers did not affect the bond strength for other three products.

Studies have shown that some resin monomers from luting agents or alloy primers are able to react 
chemically and bond with the superficial oxide layer of cast noble and base metal dental alloys (3,9,11-15). This layer is formed during casting due to the reactivity of the alloy with oxygen, nitrogen and other elements at high temperatures. For titanium, it is thin, adherent with the metallic substrate, has high chemical stability and is reformed by contact with oxygen if mechanically removed from the surface $(4,5,8)$. Before application of alloy/metal primer, the titanium surfaces were airborneparticle-abraded with aluminum oxide to remove the superficial oxide layer, to mechanically clean the surface from investment and to increase the surface bonding area. This procedure has been used in several studies to prepare the surface for bonding $(3,8,10,12)$.

Metal Primer II contains MEPS (thiophosphoric methacrylate), which promotes bonding of LinkMax resin cement to different types of metal alloys (15-17). The results of this study showed that the application of Metal Primer II increased the bond strength of LinkMax to a titanium surface. The functional monomer of Metal Primer II has a high affinity for the oxide layer created on the titanium casting surface, contributing to a high bond strength (9-11).

Little has been reported on the bond strength of Metaltite to titanium. The best results for Metaltite primer, which contains MTU-6, a thiouracil monomer, have been obtained when it was tested using precious metals (16) rather than with semiprecious metals and other dental alloys. The use of Metaltite adhesive primer did not enhance the bond strength of Bistite II DC resin cement to titanium. Also, its results were similar to Rely $\mathrm{X}$ ARC resin cement in terms of bond strength with or without adhesive primer application.

Because of the low affinity of Bis-GMA to titanium (9), RelyX ARC, which is a Bis-GMA-based resin cement, presented the lowest bond strength values. A silane-coupling agent (Ceramic Primer) was used as an adhesive primer for RelyX ARC resin cement. This silane agent is indicated to apply on conditioned surfaces of ceramics prior to resin cement and it did not change the bond strength to titanium. However, it can enhance the wettability to titanium surfaces (11-13), which may be responsible for increasing the bond strength of RelyX Unicem. This self-adhesive resin cement has greater viscosity than conventional resin cements and the wetting ability of adhesive primers is considered crucial to improve the bond strength to titanium. The improved contact between the alloy surface and the resin cement promoted by Ceramic Primer allowed and enhanced the chelation-bonding adhesive effect of the ionomeric part of RelyX Unicem to the metal ions of titanium, increasing the bond strength (18).

The use of Alloy Primer before Panavia F 2.0 did not change the bond strength. Alloy Primer contains VBATDT and MDP as functional monomers. VBATDT monomers have affinity only to some metal elements, such as gold, silver, palladium and platinum. Titanium is classified as a base metal, and therefore no interaction with VBATDT would be expected (20). However, a surface layer of metal oxides can form covalent bonds, hydrogen bonds and van der Waals forces to the monomers of resin cement. Both Alloy Primer and Panavia F 2.0 contain MDP, which has been reported to react chemically with the chromium oxide created on titanium casting surface $(2,8,17)$. Thus, the direct application of Panavia F 2.0 to titanium surface without an adhesive primer was sufficient to obtain a high bond strength $(44.1 \pm 6.9 \mathrm{MPa})$, in accordance with the parameters of bond strength testing in Restorative Dentistry (22).

Resin cements have been developed to form chemical bonds directly to surfaces or are part of cementing systems that include hydrofluoric acid, silane coupling agents, alloy primers and other materials to improve the quality of adhesion of resin cements to the surface of fixed dental prostheses $(11,14)$.

The results obtained in the present study indicate that the bond strengths of Bistite II DC, Panavia F 2.0 and RelyX ARC resin cements to titanium were not increased by adhesive primer applications; however no reduction on bond strength was observed. Thus, the priming step suggested in this study is recommended for all resin cements tested in this study.

\section{RESUMO}

O objetivo deste estudo foi avaliar o efeito da aplicação de primers na resistência de união de cimentos resinosos ao titânio. Quatro primers - Metaltite, Metal Primer II, Alloy Primer and Ceramic Primer - e seus respectivos cimentos resinosos - Bistite II DC, Link Max, Panavia F 2.0, RelyX Unicem and RelyXARC - foram testados. Placas de titânio foram preparadas a partir da fundição de lingotes ( $\mathrm{n}=6$ espécimes/cimento) e as superfícies dessas placas foram jateadas com partículas de $\mathrm{A} 12 \mathrm{O} 3(50 \mu \mathrm{m})$. Três cilindros de cimento resinoso foram construídos em cada placa de titânio, utilizando moldes transparentes com formato de cilindro e foram submetidos ao teste de microcisalhamento. Os dados foram analisados pela ANOVA (dois fatores) e teste de Tukey $(\alpha=0,05)$. A aplicação do Metal Primer II e do Ceramic Primer resultou no aumento significativo da resistência de união para os cimentos resinosos Link Max e RelyX Unicem, 
respectivamente. Os cimentos Panavia F 2.0 e o RelyX ARC mostraram altos valores de resistência de união com ou sem o uso dos primers. A aplicação dos primers pode aumentar a resistência de união dos cimentos resinosos ao titânio, dependendo do tipo de cimento resinoso utilizado.

\section{ACKNOWLEDGEMENTS}

This study was supported by grants from FAEPEX/UNICAMP (\#1186/05) and from CNPq (\#305777-2010-6), Brazil.

\section{REFERENCES}

1. Wang RR, Fenton A. Titanium for prosthodontic applications: a review of the literature. Quintessence Int 1996;27:401-408.

2. Yanagida H, Matsumura H, Taira Y, Atsuta M, Shimoe S. Adhesive bonding of composite material to cast titanium with varying surface preparations. J Oral Rehabil 2002;29:121-126.

3. Taira Y, Yanagida H, Matsumura H, Atsuta M. Effects of a metal etchant and two primers on resin bonding durability to titanium. Eur J Oral Sci 2004;112:95-100.

4. Kasemo B. Biocompatibility of titanium implants: surface science aspects. J Prosthet Dent 1983;49:832-837.

5. Strietzel R, Hösch A, Kalbfleisch H, Buch D. In vitro corrosion of titanium. Biomaterials 1998;19:1495-1499.

6. Galo R, Ribeiro RF, Rodrigues RCS, Pagnano VO, De Mattos MGC. Effect of laser welding on the titanium composite tensile bond strength. Braz Dent J 2009;20:403-409.

7. Lorey RE, Edge MJ, Lang BR, Lorey HS. The potential for bonding titanium restorations. J Prosthodont 1993;2:151-155.

8. Taira Y, Matsumura H, Yoshida K, Tanaka T, Atsuta M. Influence of surface oxidation of titanium on adhesion. J Dent 1998;26:6973.

9. Taira Y, Yoshida K, Matsumura H, Atsuta M. Phosphate and thiophosphate primers for bonding prosthodontic luting materials to titanium. J Prosthet Dent 1998;79:384-388.

10. Yanagida H, Taira Y, Shimoe S, Atsuta M, Yoneyama T, Matsumura H. Adhesive bonding of titanium-aluminum-niobium alloy with nine surface preparations and three self-curing resins.
Eur J Oral Sci 2003;111:170-174.

11. Schneider R, De Goes MF, Henriques GE, Chan DC. Tensile bond strength of dual curing resin-based cements to commercially pure titanium. Dent Mater 2007;23:81-87.

12. Suese K, Kawazoe T. Ready-made post and core systems, with special reference to the threaded post. Hotetsu Rinsho 1984;17:7484.

13. Ozcan M, Valandro LF. Effect of silane coupling agents and alloy primers on adhesion to titanium. Minerva Stomatol 2011; 60:427434.

14. Ozcan M, Valandro LF. Bond strength of two resin cements to titanium after different surface conditioning methods. Gen Dent 2012; 60: e6-e12.

15. Ohkubo C, Watanabe I, Hosoi T, Okabe T. Shear bond strengths of polymethyl methacrylate to cast titanium and cobalt-chromium frameworks using five metal primers. J Prosthet Dent 2000;83:5057.

16. Kojima K, Kadoma Y, Imai Y. Adhesion to precious metal utilizing triazine dithione derivative monomer. J Jpn Soc Dent Mater Devices 1987;6:702-707.

17. Matsumura H, Kamada K, Tanoue N, Atsuta M. Effect of thione primers on bonding of noble metal alloys with an adhesive resin J Dent 2000;28:287-293.

18. Hansson O. Strength of bond with comspan opaque to three silicoated alloys and titanium. Scand J Dent Res 1990;98:248-256

19. Rocha SS, Adabo GL, Henriques GEP, Arruda Nóbilo MAA Vickers hardness of cast commercially pure titanium and Ti-6Al4V alloy submitted to heat treatments. Braz Dent J 2006;17:126129.

20. Hansson O, Moberg LE. Evaluation of three silicoating methods for resin-bonded prostheses. Scand J Dent Res 1993;101:243-251.

21. Shimada Y, Senawongse P, Harnirattisai C, Burrow MF, Nakaoki $\mathrm{Y}$, Tagami J. Bond strength of two adhesive systems to primary and permanent enamel. Oper Dent 2002;27:403-409.

22. Pashley DH, Sano H, Ciucchi B, Yoshiyama M, Carvalho RM Adhesion testing of dentin bonding agents: a review. Dent Mater $1995 ; 11: 117-125$. 